\title{
Application of functional genomics to primate endometrium: insights into biological processes Linda C Giudice*
}

\author{
Address: Department of Obstetrics, Gynecology and Reproductive Sciences, University of California, San Francisco, 505 Parnassus, M1496, Box \\ 0132, San Francisco, CA 94143-0132, USA \\ Email: Linda C Giudice* - giudice@obgyn.ucsf.edu \\ * Corresponding author
}

from Basic and applied biology of the primate reproductive tract: in honor of the career of Dr Robert M Brenner Portland, Oregon, USA. 16-17 August 2005

Published: 9 October 2006

Reproductive Biology and Endocrinology 2006, 4(Suppl I):S4 doi:I0.II86/I477-7827-4-SI-S4

(C) 2006 Giudice; licensee BioMed Central Ltd.

This is an open access article distributed under the terms of the Creative Commons Attribution License (http://creativecommons.org/licenses/by/2.0), which permits unrestricted use, distribution, and reproduction in any medium, provided the original work is properly cited.

\begin{abstract}
Endometrium is a dynamic tissue that responds on a cyclic basis to circulating levels of the ovarianderived steroid hormones, estradiol and progesterone. Functional genomics has enabled a global approach to understanding gene regulation in whole endometrial tissue in the setting of a changing hormonal milieu. The proliferative phase of the cycle, under the influence of estradiol, has a preponderance of genes involved in DNA synthesis and cell cycle regulation. Interestingly, genes encoding ion channels and cell adhesion, as well as angiogenic factors, are also highly regulated in this phase of the cycle. After the LH surge, different gene expression profiles are uniquely observed in the early secretory, mid-secretory (window of implantation), and late secretory phases. The early secretory phase is notable for up-regulation of multiple genes and gene families involved in cellular metabolism, steroid hormone metabolism, as well as some secreted glycoproteins. The mid-secretory phase is characterized by multiple biological processes, including up-regulation of genes encoding secreted glycoproteins, immune response genes with a focus on innate immunity, and genes involved in detoxification mechanisms. In the late secretory phase, as the tissue prepares for desquamation, there is a marked up-regulation of an inflammatory response, along with matrix degrading enzymes, and genes involved in hemostasis, among others. This monograph reviews hormonal regulation of gene expression in this tissue and the molecular events occurring therein throughout the cycle derived from functional genomics analysis. It also highlights challenges encountered in using human endometrial tissue in translational research in this context.
\end{abstract}

\section{Background}

Human endometrium, the anatomic prerequisite for continuation of the species, is a dynamic tissue that responds to the circulating steroid hormones, estradiol $\left(\mathrm{E}_{2}\right)$ and progesterone $(\mathrm{P})$, throughout normal menstrual cycles (Figure 1; and [1], review). The goals of orchestrated events in endometrium are to permit successful nidation of a conceptus, and in the absence of such, desquamation of the tissue and subsequent regeneration. While the window of implantation is a temporally and spatially defined time in the endometrial cycle in which blastocyst implantation can begin, events prior to it are critical in optimiz- 
ing endometrial receptivity to embryonic implantation in this time frame. In the absence of implantation, orderly shedding of the tissue and hemostasis are essential to prevent morbidities of hypermenorrhea, menorrhagia and anemia ([1], review).

There are numerous approaches to assess endometrial function, including (a) direct observation through, e.g., hysteroscopy or gross examination of the tissue; (b) imaging techniques, including ultrasound and magnetic resonance imaging; and (c) endometrial biopsy or hysterectomy specimen tissue sections and (i) subsequent hematoxylin and eosin staining and/or immunohistochemical or in situ hybridization analysis for specific gene products and/or (ii) simultaneous analysis of multiple genes and gene products by array analyses for gene expression and proteins. The latter approaches (ii) have been relatively recent events, in contrast to histologic evaluation of cycle-dependent changes in endometrium, first described over half a century ago [2]. It should be noted that histology has been the classical approach for evaluation of adequacy of the endometrium for fertility and normalcy of the endometrium in clinical conditions of abnormal uterine bleeding, where, e.g., polyps, fibroids, and endometrial hyperplasia and/or cancer have been suspected. This type of evaluation is standard of care in the clinical setting where abnormal uterine bleeding or unusual findings on ultrasound or at hysteroscopy and hysterectomy have been made. However, recent studies have called into question the utility of the endometrial biopsy as a clinical tool for fertility evaluation and for research because there is significant inter- and intra-observer variability and histologic delay fails to discriminate between fertile and infertile couples [3]. Also, Murray and colleagues have demonstrated that histologic features fail to distinguish reliably specific menstrual cycle days or narrow intervals of days [4]. Furthermore, histology rarely gives insight into the molecular mechanisms occurring in the tissue throughout the cycle, which may be accomplished through molecular phenotyping. Questions that arise about molecular phenotyping of human endometrium include whether this approach can (a) distinguish among the phases of the cycle; (b) define receptivity to embryonic implantation; (c) identify a variety of endometrial disorders not apparent from histologic evaluation of the tissue; and (d) give insight into molecular events that occur dynamically throughout the cycle.

The genomic era has heralded a new approach for simultaneous analysis of genes and proteins in tissues, and this monograph describes gene expression studies performed on whole endometrial tissue in women and non-human primates. The major limitation of such studies is that gene transcription alone has been investigated in the absence of investigation into the corresponding proteome. The lat- ter would not only confirm gene expression profiling, but also would give insight into proteins and protein modifications that participate in biological processes during the endometrial cycle. Furthermore, a proteomic approach would be welcome to detect changes in secreted proteins and soluble endometrial biomarkers across the cycle and in endometrial disorders. While elucidation of the genome has been an extraordinary accomplishment during the past decade, elucidation of the proteome, technologically even more challenging and expensive, must be conducted for a more accurate assessment of endometrial physiology and pathophysiology.

\section{Challenges in Using Human Tissues}

The endometrium is comprised of zones that include the functionalis (shed on a monthly basis) and the basalis (believed to be the origin of cells for regeneration of the tissue) ([1], review). These zones are clearly identifiable by the naked eye in hysterectomy specimens, although they are not separated by an anatomic barrier (e.g., membrane), and thus tissue sampling often includes some cell populations from each layer. This is particularly true with currettings from hysterectomy specimens. Less contamination from basalis endometrium is encountered in endometrial biopsies, where the functionalis is the primary layer sampled. In addition, biopsies or selecting only a portion of tissue in hysterectomy specimens may result in different complements of cell types in different specimens analyzed. This can lead to significant variability in genes expressed in tissue biopsies during the same cycle phase and in specimens compared in different phases across the cycle. These issues are important to consider in experiments designed to evaluate whole tissue genome or proteome expression.

Obtaining normal human tissue, and in particular, normal hormone-dependent tissues from cycling women, for biochemical analysis is a challenge and underscores some important issues associated with this type of translational research. Endometrial specimens should be obtained from the fundus, and the operator should be careful to avoid non-hormone-dependent parts of the endometrium, such as the periostia. Furthermore, accurate subject history annotation is important, as steroid hormones have significant effects on endometrial function and gene expression, and excluding recent exogenous steroid hormone use is essential. Even in this setting, obtaining sufficient tissue for analysis can sometimes be a challenge, as well as excessive blood in specimens to be analyzed.

Perhaps one of the most challenging issues, however, is how to define normal endometrial tissue. Most samples are obtained from subjects undergoing hysterosocopy and/or endometrial biopsy or hysterectomy for clinical 

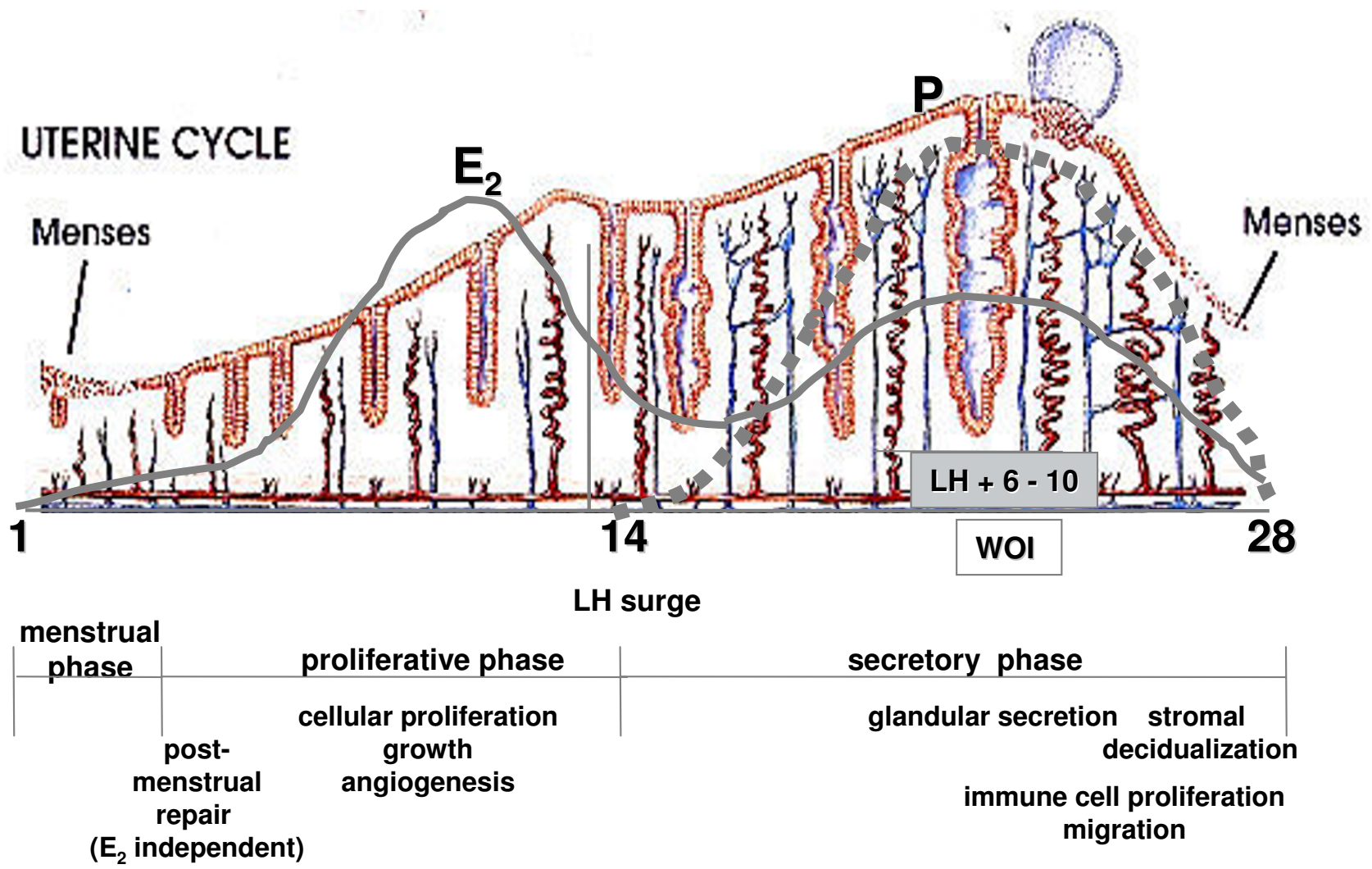

LH surge
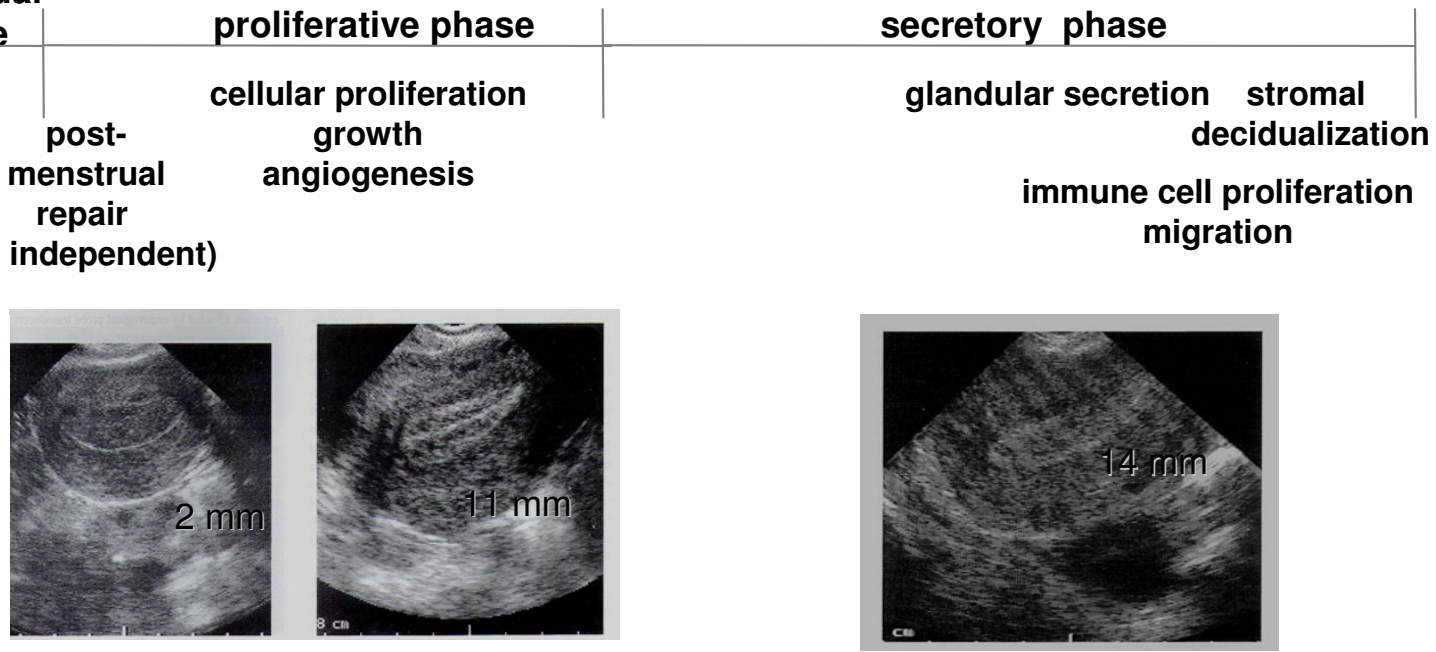

\section{Figure I}

Cyclic changes in endometrium across the cycle. Shown are hormonal profiles, cycle phases and sub-stages, and ultrasonographic appearance of the endometrium in early proliferative, late proliferative, and mid-secretory phases. Reproduced with permission of Adeza Biomedical.

indications such as infertility, abnormal uterine bleeding, uterine fibroids, uterine prolapse, pelvic pain, and endometriosis. It is rare to obtain endometrial tissue from normal cycling subjects not on contraceptive steroids and willing to donate their endometrium to science. Thus, subject selection and carefully documented and validated medical and surgical histories are critical to obtaining data that are reproducible and meaningful.

\section{Endometrial gene profiling}

Several investigators have recently reported results of cDNA and oligonucleotide array analyses of endometrial gene expression in humans and non-human primates.
Figure 2 summarizes these studies with regard to phases of the cycle analyzed, primarily for pair wise analyses [5-12], although two studies investigated gene expression across the cycle $[13,14]$. Herein, we focus on the global gene expression profiling of human endometrium across the menstrual cycle and select pair-wise comparisons of phases in the studies of Talbi, Hamilton et al [14] and Ponnampalan et al [13], which used whole genome 54,600 genes and ESTs on high density oligonucleotide microarrays and 13, 600 cDNA arrays, respectively.

In the study by Talbi, Hamilton, et al [14], 46 subjects were recruited, but only 22 had endometrial samples that 


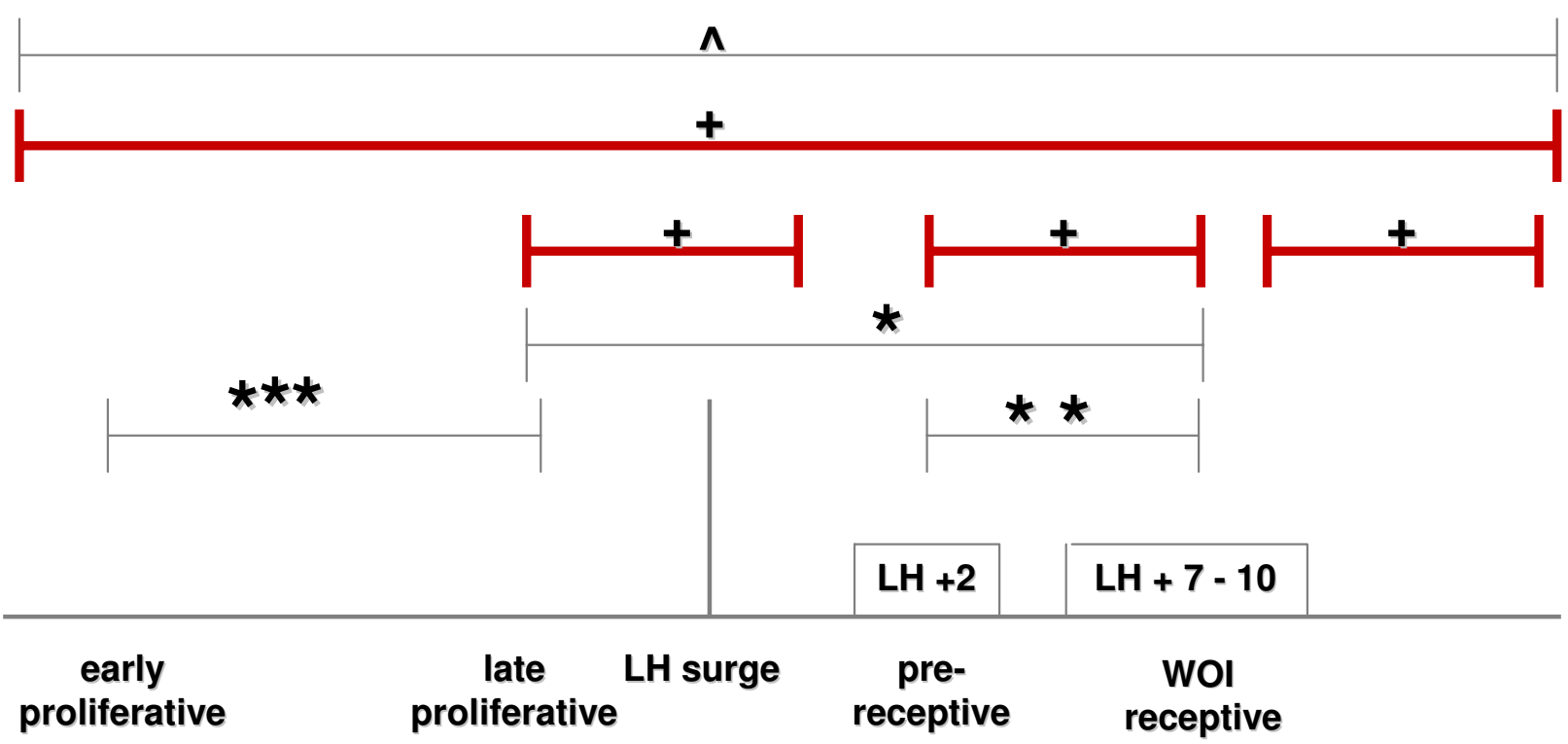

Figure 2

Schematic representation of microarray studies comparing cycle phases in women and non-human primates. (See text). Symbols correspond to citations: * $[5,7,9] ; * *[6,8,1 \mathrm{I}, \mathrm{I} 2] ; * * *[10] ;{ }^{\wedge}[13] ;+[$ [14]. With permission from reference [I4].

yielded sufficient and good quality RNA for subsequent microarray analysis. Six samples either had different histologic readings from two or more pathologists or had a histologic evaluation by only one pathologist and were designated as "ambiguous". This study provided the first, whole genome-wide gene, gene ontology, and gene clustering analyses across the entire menstrual cycle in normoovulatory women. Different data analyses were conducted to determine how samples clustered together (Figures 3 and 4). A completely unbiased approach, principal component analysis (PCA, Figure 3 ), used the entire gene set (54,600 probe sets); whereas hierarchical clustering analysis (Figure 4) used a more limited gene set $(7,231$ probe sets from pair-wise comparisons of early secretory (ESE) vs. proliferative (PE), mid-secretory (MSE) vs. ESE, and late-secretory (LSE) vs. MSE)). These analyses demonstrate several important points: (a) PCA analysis reveals that samples with known histology cluster into cycle phases; (b) hierarchical clustering reveals that samples with known histology cluster into the same cycle phases as observed with the PCA analysis; (c) hierarchical clustering analysis reveals two major branches and several subbranches, with PE and ESE clustering together in the first major branch and MSE and LSE in the second major branch (Figure 4); (d) hierarchical clustering reveals that samples have unique molecular profiles; (e) samples with unknown or "ambiguous" histology cluster into cycle phases that are the same by both PCA and hierarchical clustering analysis; (f) samples cluster independently of how they were obtained (biopsy or curetting); and (g) samples cluster independent of the clinical indication for which the "normal" specimen was obtained. Thus, this study demonstrates that assignment of menstrual cycle stage of ambiguous samples, based on their gene expression profiles and their cluster grouping, is a powerful adjunct to the historical histological "gold standard" of endometrial assessment. Furthermore, it demonstrates that samples obtained at any time in the cycle have unique molecular signatures that preclude the need to assign a histologic phase to the sample a priori. While unique gene signatures lead to clustering in groups (phases), it is interesting that the molecular signatures are not identical (Figure 4) and may be the result of, e.g., subject-to-subject variability and different complements of cell types in different specimens.

The study of Ponnampalan et al [13] used cDNA microarrays to study endometrial gene expression across the menstrual cycle. The investigators performed initial hierarchical clustering analysis of 43 endometrial samples that revealed two main branches: one containing menstrual (M), early (EPE)-mid (MPE) proliferative, late proliferative (LPE), and ESE-MSE, and the second containing $M, M / E P E, M S E, L S E$, and LSE/M. Six outliers were subsequently removed for disagreement of histologic stage between two pathologists or for poor hybridization, and 


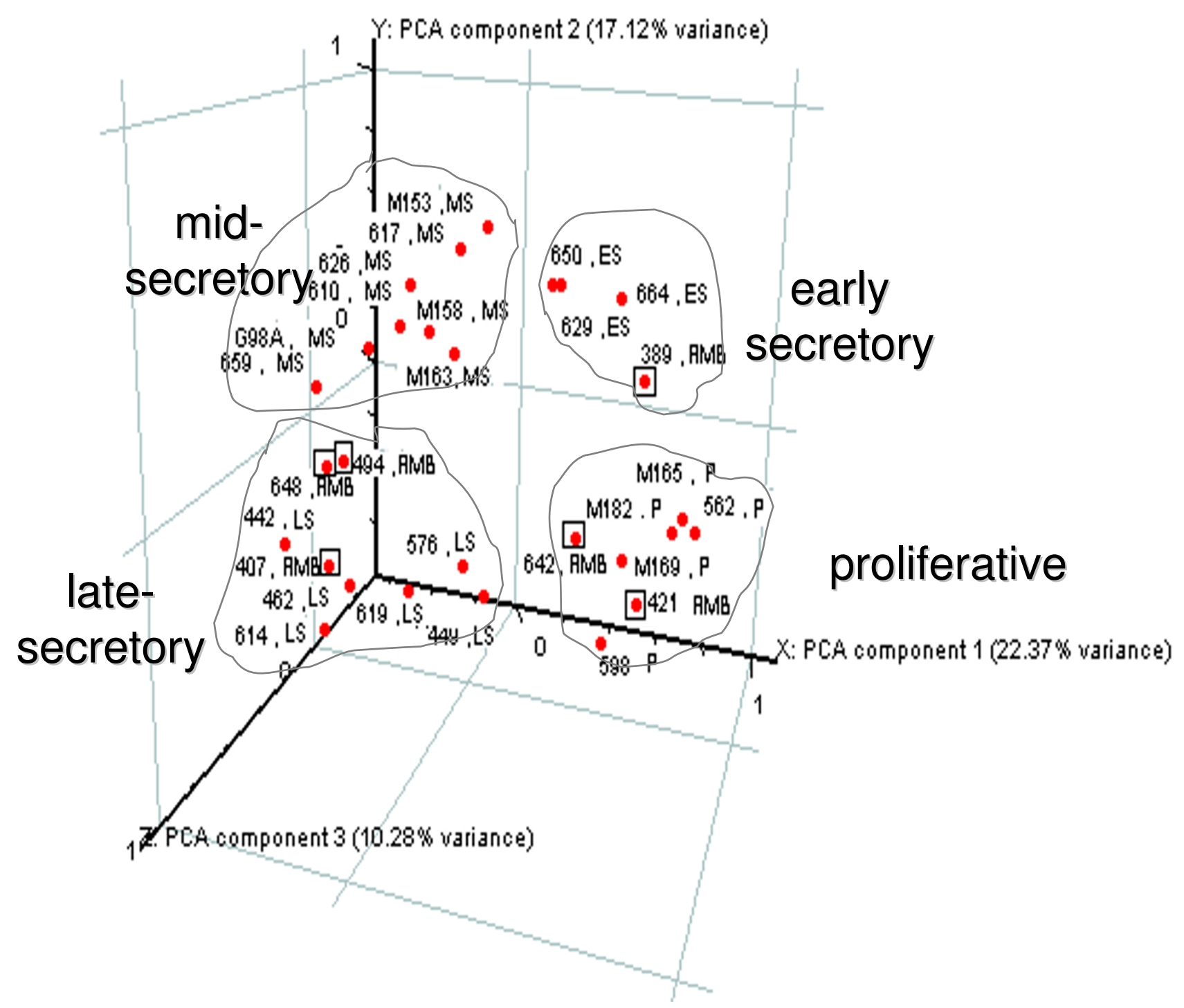

Figure 3

Gene clustering in the endometrium: Principal component analysis (PCA) of human endometrium across the menstrual cycle. PCA was applied to all endometrial samples, and numbers refer to individual sample labels. "Ambiguous samples" (see text) are labeled AMB (dots in squares). Analysis reveals clustering of samples into cycle phases. With permission from reference [14].

this resulted in two main branches for 37 samples. One branch contained M, EPE-MPE, LPE-ESE, and ESE-MSE and the other contained M, MSE-LSE, and LSE-M. Some cycle phases had too few samples for analysis, and these (MSE and LSE) were then merged. Thus, it is difficult to compare gene directly expression profiles between these two studies, due to these different approaches for data analysis, as well as different platforms for hybridization.

\section{Early Secretory vs. Proliferative Endometrium}

During the proliferative phase, endometrium is stimulated by high levels of circulating $\mathrm{E}_{2}$, and then after ovulation in the early secretory phase, it is the target of low, but rising, circulating levels of $\mathrm{P}$ (and $\mathrm{E}_{2}$ ). Thus, genes regulated in ESE vs. PE may be regulated by $\mathrm{E}_{2}$ and/or P. With regard to $\mathrm{E}_{2}$-regulated genes, insight into these derive from a recent study on gene expression in human 


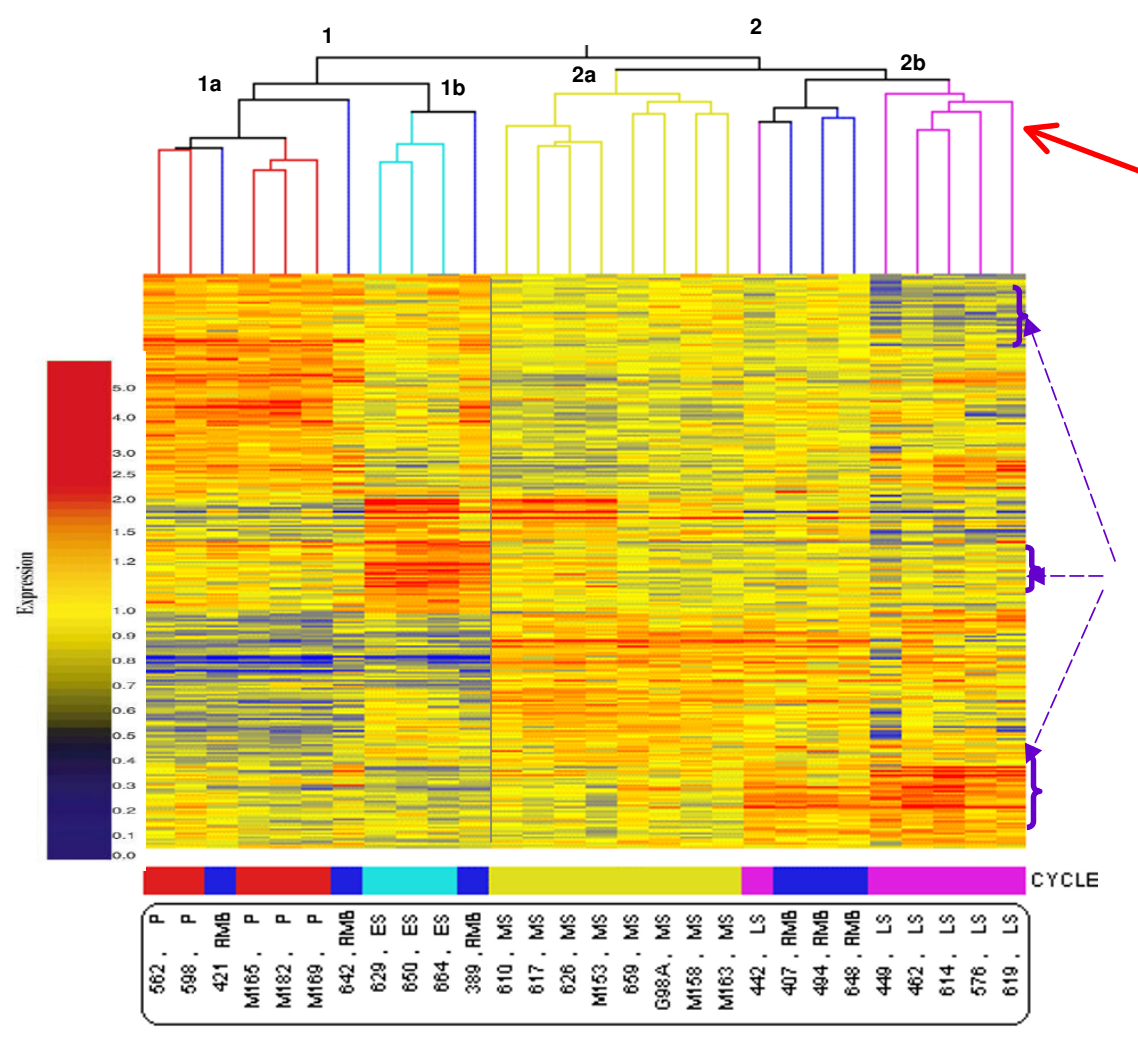

\title{
"Heatmap"
}

\author{
Dendrogram along top: \\ different samples that have \\ gene expression profiles \\ similar to one another
}

\section{Gene clusters along sides: groups of similarly expressed genes}

\section{Figure 4}

Gene clustering in the endometrium: Gene expression profiling across the menstrual cycle. The Heatmap represents relative gene expression levels in the endometrial samples across the menstrual cycle. Each horizontal line represents a single gene, and each column represents a single sample. Samples cluster by cycle phase (bar at bottom of the Heatmap: proliferative (red), early-secretory (light blue), mid-secretory (olive), late secretory (purple) and ambiguous samples (dark blue). Relative expression of each gene is color-coded: high (red) or low (blue), as indicated in the color legend on the left side of the figure. Hierarchical clustering reveals sample clustering into cycle phases and unique molecular profiles. Adapted from [14], with permission.

endometrium in late PE (LPE, high $\mathrm{E}_{2}$ ) compared to menstrual endometrium (very low $\mathrm{E}_{2}$ levels) and $\mathrm{E}_{2}$-treated endometrial explants, using the same Affymetrix platform [10]. Genes up-regulated in LPE vs. menstrual endometrium included oviductal glycoprotein-1, connexin-37, olfactomedin-1, SFRP4; and down-regulated genes included MMPs-1, -3 , and -10, IL-1b, IL-8, -11, inhibin bA, SOX4 [10]. In the study by Talbi, Hamilton et al [14], olfactomedin-1 was down-regulated in ESE, suggesting that $\mathrm{P}$ inhibits its expression in this phase of the cycle. SOX4 was down regulated in LP vs. menstrual endometrium [10], and it is also down-regulated in ESE vs. PE [14], suggesting that $E_{2}$ down-regulates this gene. A recent study on global gene expression $(12,000$ genes/ ESTs) demonstrated that $E_{2}$ treatment of human endometrial cells resulted in up-regulation of N-cadherin [15]. However, N-cadherin was down-regulated in ESE vs. PE [14], suggesting that $\mathrm{N}$-cadherin expression is inhibited by $\mathrm{P}$. Of interest, also, is the up-regulation of FOXO1A (2.1-fold) in ESE vs. PE [14], especially in view of recent data in breast cancer cells that demonstrate the importance of FOXO1A in $\mathrm{E}_{2}$ action [16].

In a recent study by Tan et al [17], global gene profiling of mouse uterus during the estrous cycle was investigated and revealed up-regulation of 17bHSD-2 in estrus versus diestrus. This gene is the highest up-regulated gene in ESE vs. PE in human endometrium[14]. Although the data in mouse uterus suggest that it is $\mathrm{E}_{2}$-regulated, data are convincing that $17 \mathrm{bHSD}-2$ in human endometrium is regulated via PR in the stroma, with paracrine factors upregulating it in the epithelium [18]. Up-regulation of 17bHSD-2 in human ESE vs. PE is also consistent with results from Mustonen et al [19]. The up-regulation of $17 \mathrm{bHSD} 2$ suggests that direct $\mathrm{E}_{2}$ action in this phase is beginning to be curtailed, as a prelude to more pro- 
nounced curtailment in the mid-secretory phase in which estrogen receptors are down-regulated in the stroma and nearly completely absent in the epithelium [20-23].

Several genes are up-regulated in ESE vs. PE that are worthy of mention, including MUC-1, Dkk-1 and other Wnt family members, and IL-15 [14]. MUC-1 maintains hydration of cell surfaces, lubricates them, and protects from microorganisms and degradative enzymes [24]. In mouse uterus it is stimulated by $\mathrm{E}_{2}$, but it is highly up-regulated in the secretory phase in human endometrium and is presumably P-regulated [24]. Dkk-1 is up-regulated $>6$-fold in ESE vs. PE, and recent data from our laboratory demonstrate that it is a P-regulated gene in endometrial stromal cells [25]. IL-15 is P-regulated and is important as a chemoattractant and stimulator of NK cell replication $[26,27]$.

ESE is characterized by inhibition of cellular mitosis, in marked contrast to the mitotic activity that occurs in PE, and the down-regulation of numerous growth factors in this phase further supports this conclusion [14]. Furthermore, the shift to cellular metabolism in this phase of the cycle, compared to PE, underscores that ESE is biosynthetically active, likely in preparation for embryonic implantation.

\section{Mid Secretory vs. Early Secretory Endometrium}

The mid-secretory phase is replete with numerous biological processes and molecular participants that coordinately facilitate embryonic implantation. This is the most well characterized phase of the cycle, with regard to gene expression analysis $[6,8,11,14]$. Despite the fact that these studies all used similar platforms, the number of genes in common among ALL studies in different gene ontology categories is surprisingly low. Of the 75 genes up-regulated in MSE vs. ESE in the study by Riesewijk et al [8], 41 are identical to up-regulated genes in the study by Talbi, Hamilton et al [14], and of the 56 down-regulated genes, 11 were the same. Of the 74 genes encoding cell surface components, extracellular matrix components, growth factors, and cytokines in MSE vs. ESE in the study by Carson et al [6], 11 were in common, and of the 76 down-regulated genes, only one was in common with Talbi, Hamilton et al [14]. Of the 49 up-regulated genes in MSE vs. ESE in the study by Mirkin et al [11], 14 are similarly regulated, and of the 58 that were down-regulated, only 3 are common to Talbi, Hamilton et al [14]. These differences likely are due to multiple factors, including different chip versions, different hybridization conditions, scanners, and statistical programs for data analyses, subject-tosubject variability, where in endometrium samples were obtained (fundus, lower uterine segment, periostium), different complements of cellular components in individual samples, and precisely the time in the cycle when samples were obtained. With regard to the latter, e.g.,
Reisewick et al [8]) obtained endometrial tissue strictly at 2 and 7 days after the LH surge; whereas, most other studies have samples that span groups of days in a particular phase.

\section{Up-Regulated Genes}

Gene families that were up-regulated in MSE vs. ESE are relevant to the cellular differentiation and cell-cell communications that underlie receptivity to embryonic implantation. These include the processes of cell adhesion, suppression of cell proliferation, regulation of proteolysis, metabolism, growth factor and cytokine binding and signaling, immune and inflammatory responses, and the responses to wounding and stress [14]. Striking upregulation was observed with genes encoding secreted proteins, cytokines and genes involved in detoxification mechanisms. In the study of Ponnampalam et el [13], pair-wise comparison of genes expressed in MSE vs. ESE was not reported, and thus comparisons between the data sets is not possible.

\section{Immune genes}

The most-highly up-regulated gene (61-fold) in MSE vs. ESE is CXCL14, a chemokine that is also known as breast and kidney expressed chemokine (BRAK). It recruits monocytes in the setting of inflammation and without inflammation [28], and it may be a major recruiter of monocytes and other cell types to endometrium during the implantation window. Leukemia inhibitory factor (LIF) is significantly highly up-regulated in MSE vs. ESE $[14,29]$. It plays a central role in endometrial receptivity in the mouse [30,31], and increasing evidence suggests that it is also important in humans [32]. For example, in some women with infertility and repetitive miscarriage, low levels of LIF in MSE have been reported [33,34], as have point mutations in the coding region of the LIF gene [32]. The data set reveals, overall, an up-regulation of genes involved in activation of the innate immune response, including members of the complement family, antimicrobial peptides, and Toll-like receptor expression [14]. There is also enhancement of chemotaxis of monocytes, T cells, and NK cells by candidate genes CXCL14, granulysin, IL15 , carbohydrate sulfotransferase 2, and suppression of NK and T-cell activation. IL-15 is regulated by P (see above), and recent evidence suggests a central role for IL15 in secretory phase endometrium in the recruitment of peripheral blood CD16-NK cells into the tissue in this phase of the cycle [35]. Many of the genes observed in our data set were also observed in the data from Carson et al [6], Riesewijk et al [8], and Mirkin et al [11]. The gene expression profiles are consistent with the marked increase in lymphocyte infiltration $[2,36]$. 


\section{Secretory proteins}

Other genes that were highly up-regulated include cysteine-rich secretory protein (CRISP) 3 and secretoglobin family 2A member 2, believed to be important in embryonic attachment, although other functions may exist in this time of the cycle.

\section{Detoxification}

Among the most highly up-regulated genes are those encoding glutathione peroxidase-3 (GPX-3) and metallothioneins (MT) 1G,1H,1E,1F, $1 \mathrm{~L}, 1 \mathrm{X}$, and $2 \mathrm{~A}$. The former is consistent with prior observations $[8,11]$ (and in MSE vs. PE $[5,7,37])$. GPXs (anti-oxidants) and metallothioneins protect cells from unstable reactive radicals and heavy metals [38]. These are likely to protect an embryo from free radicals and heavy metals in the very beginning phases of implantation. Interestingly, GPXs are selenium-dependent, and women with selenium deficiency have a higher rate of infertility and miscarriage [39].

\section{Down-regulated genes}

Among the most highly down-regulated genes in MSE vs. ESE are secreted frizzled related protein (SFRP), olfactomedin 1 , the progesterone receptor (PR), PR membrane component 1, ER-a, MUC-1, 17bHSD-2, and MMP-11 [14]. Many were not found to be regulated in earlier MSE vs. ESE microarray studies, likely due to reasons listed above for differences in up-regulated genes among various studies.

\section{Progesterone regulated genes}

Analysis of genes expressed in various phases of the menstrual cycle can give insight into genes that are candidates for regulation by $\mathrm{P}$. Of interest is the regulation of genes in MSE vs. PE from all studies in humans and non-human primates $[5,7,9]$ that are in common with those regulated in ESE vs. PE [14] and MSE vs. ESE [6,8,11,14]. The result of this comparison is shown in Figure 5 . These genes are likely to be regulated by $\mathrm{P}$, either directly or indirectly, although validation of such regulatory mechanisms awaits further investigation. Analysis of PREs and EREs by Borthwick et al [7] and Mirkin et al [11] support some of these conclusions, as do studies using anti-progestins and PR knock out of P-regulated genes in mouse uterus/ endometrium [40].

\section{Late Secretory vs. Mid Secretory Endometrium}

The transition from mid-secretory to late secretory endometrium, in the absence of embryonic implantation, is characterized by $P$ withdrawal and preparation for desquamation of the tissue and menstruation. Accordingly, gene expression profiling reveals changes in genes involved in the extracellular matrix, the cytoskeleton, cell viability, vasoconstriction, smooth muscle contraction, hemostasis, and transition in the immune response to include an inflammatory response $[14,41,42]$.

\section{Extracellular matrix degradation}

In the microarray data set for LSE vs. MSE, striking up-regulation of metalloproteinases (MMPs and ADAMs), serine proteases [the plasminogen activators, uPA (PLAU) and tPA (PLAT)], and their inhibitors, was observed [14]. This is consistent with declining $\mathrm{P}$ levels within the tissue at this time of the cycle and concomitant dysinhibition of expression of these genes. $P$ also inhibits leukocyte transit into the endometrium [43], a process that is controlled in the secretory phase by the stromal cell, the main cell type that retains PR in this phase of the cycle [20-23]. uPA (PLAU) is up-regulated in LSE compared to MSE, and can activate TGFb1 [44]. It is regulated by tissue factor which is also P-dependent, and it activates plasminogen which can further activate MMPs [45]. Thus, it is likely that uPA plays a major role in preparing the tissue for desquamation. Another group of genes that are important in endometrial breakdown are members of the TGFb family. For example, endometrial bleeding associated factor (EBAF) is one of the most highly up-regulated genes in LSE vs. MSE [14]. EBAF stimulates expression proMMP-3 and -7 in proliferative phase human endometrial explants, and $P$ inhibits this as well as inhibition of EBAF expression [46]. Importantly, these genes are up-regulated, but tissue breakdown does not occur. This programming of the endometrium in the late-secretory phase appears to be inhospitable for embryonic implantation and must be carefully regulated, temporally, for menses to occur at an appropriate threshold of gene activation, and to permit subsequent repair of the tissue for the next cycle.

\section{Immune activity}

The immune gene regulation observed in LSE vs. MSE [14] reflects known histologic observations of an influx of polymorphonuclear leukocytes [2,36]. Fc receptors, MHC molecules, NK molecules and T cell molecules are all upregulated, and it appears that the system is preparing for immune action involving innate and adaptive immunity ( $\mathrm{T}$ cell specific, and antibody-mediated). The profile of genes suggests a pro-inflammatory response, with up-regulation of IL-1, a pro-inflammatory cytokine that induces $\mathrm{T}$ cell activation. In addition, IL-b and TNF-a produced by leukocytes in the stromal compartment in the late secretory phase, stimulate release of matrix degrading enzymes that contribute to the breakdown of the vascular basement membrane and connective tissue integrity in the functionalis layer $[47,48]$. Also, numerous molecules in $\mathrm{T}$ cell signaling/activation are up-regulated [14]. In addition to IL-1b, other key inflammatory mediators, e.g., CXCL8 (IL-8), CCL2 (MCP-1) $[42,49]$, and the synthesis of prostaglandins, by induction of COX-2 $[49,50]$ are all up-regulated in response to withdrawal of $P$. The microarray data 


\begin{tabular}{|ll|lc|}
\hline & UP & & DOWN \\
\hline secretoglobins & aldehyde dehydrogenase I & MMP-11 & proenkephalin \\
ostepontin & MUC-1 & MMP-7 & CXCL12 \\
aquaporin 3 & metallothionein 1G & SFRP1 & SOX4 \\
LRP4 & GABA receptor $\pi$ subunit & Wnt 5A & TGFb1 \\
DKK-1 & & Tenascin C & MSX2 \\
MAO-A & & N-Cadherin & Sema2AE \\
& & & \\
\hline
\end{tabular}

\begin{tabular}{|ll|l|}
\multicolumn{2}{|c|}{ MSE vS. ESE AND MSE vS. PE } \\
\hline \multicolumn{2}{|c|}{ UP } & DOWN \\
\hline glycodelin & GABA R $\pi$ subunit & CRSP2 \\
gastrin & claudin 4 & SFRP1 \\
osteopontin & IL-15 & Olfactomedin 1 \\
secretoglobins & Apo D & MSX2 \\
glutathione peroxidase Apo E & Osteoblast specific factor \\
solute carrier family 1, arginase 2 & NDRG3 \\
member 4 & annexin A4 & Progesterone receptor \\
monocarboxylic acid & DKK-1 & Membrane component 1 \\
carrier & GOS2 & Oviductal glycoprotein-1 \\
Transmembrane 4 & metallothioniens 1G, 1E, 2A, 1F & MMP-11 \\
superfamily member & n-acetylglucosamine-6-O- & \\
COMP & sulfotransferase & \\
MAO-A & transcobalamin & \\
aquaporin 3 & & \\
\hline
\end{tabular}

\section{Figure 5}

Candidate progesterone-regulated genes in human endometrium. Candidate genes were derived from genes common to the comparisons between early secretory endometrium (ESE) vs. proliferative endometrium (PE) and mid-secretory endometrium (MSE) vs. ESE (upper panel) and MSE vs. ESE and MSE vs. PE. With permission from (I4).

are consistent with a major shift from an innate immune response in MSE to an inflammatory response in LSE $[51,52]$. Such an inflammatory environment, along with up-regulation of matrix degrading enzymes and cellular apoptosis, teleologically would not be a receptive environment for embryonic implantation. Indeed, we have suggested that gene expression profiles in LSE vs. MSE may serve to define closure of the receptive period and the onset of the subsequent non-receptive period of endometrial development in normal, non-conception cycles. Of interest are the patterns of immune gene regulation in LSE in a conception cycle and the cross-talk between the implanting conceptus and the maternal decidua.

\section{Summary}

Microarray analyses have provided global inspection of the endometrium across the cycle and insight into the biological processes occurring therein. A schematic summary of this is presented in Figure 6. It is likely that there are microenvironments in which some processes are occurring more than others, as proximity to vascularity and immune cells may affect endometrial cellular function and vice-versa. Remarkably in normally cycling women, there is a regularity of cycle length that persists cycle-tocycle, with efficient tissue desquamation and self-limited bleeding. Abnormalities in cycle length and receptivity to embryonic implantation, as well as endometrial bleeding disorders and other endometrial pathologies likely reflect significant changes in endometrial gene expression and (dys)regulation. Microarray analyses reviewed herein are but the beginning of a compendium of genes identified in understanding the dynamic changes in morphology and function of the endometrium in health and disease. These approaches also offer the opportunity to identify abnormalities in endometrium (e.g., endometrial hyperplasia, cancer, endometriosis, endometrial polyps, and in the setting of hyperandrogenemia and hyperinsulinemia). Furthermore, they enable elucidation of the molecular basis 


\section{Summary of Events Across the Cycle from Microarray Analyses}

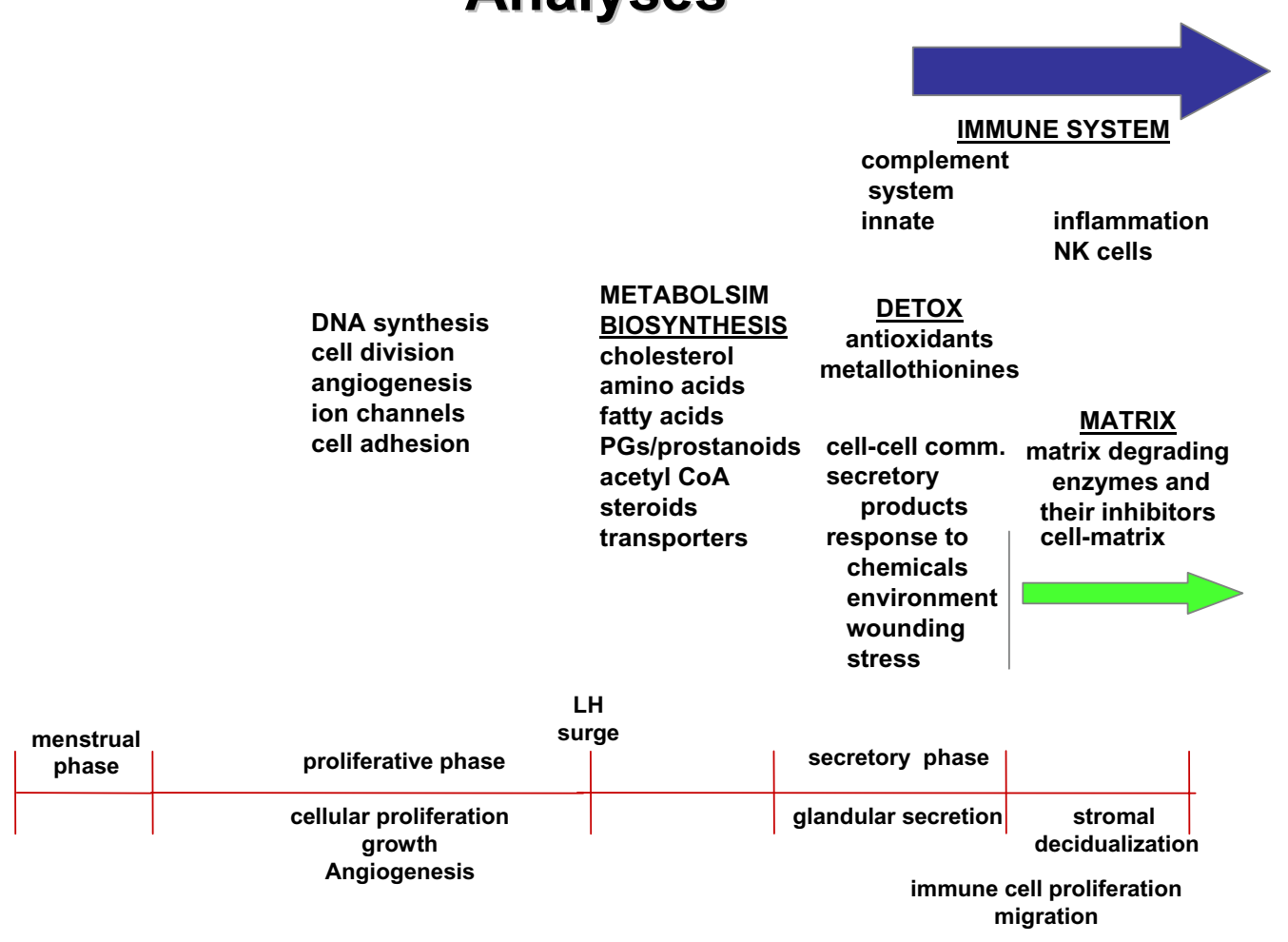

Figure 6

Summary of events occurring across the menstrual cycle, deduced from microarray analyses. (See text).

of these, as well as morphometric changes in the endometrium accompanying, e.g., different types of ovarian stimulation for infertility treatment [53]. They also provide the opportunity to define molecular mechanisms predisposing to abnormal implantation and placentation resulting in, e.g., infertility, recurrent miscarriage and intrauterine fetal growth restriction. Importantly, gene expression profiling can be used to develop molecular diagnostics of endometrial normalcy and abnormalities and identifying molecular targets for therapeutic purposes in endometrial disorders.

\section{Acknowledgements}

This monograph is dedicated to Dr Robert Brenner on the occasion of his retirement symposium in honor of his extraordinary investigative career that has contributed significantly to our understanding of the primate endometrium. Support was provided, in part, by the NIH Specialized Cooperative Centers Program in Reproduction Research HD \#31398-09 (LCG).

This article has been published as part of Reproductive Biology and Endocrinology Volume 4, Supplement I, 2006: Basic and applied biology of the primate reproductive tract: in honor of the career of Dr Robert M Brenner. The full contents of the supplement are available online at http://www.rbej.com/ supplements/4/SI.

\section{References}

I. Hess AP, Nayak NR, Giudice LC: Oviduct and endometrium: cyclic changes in the primate oviduct and endometrium. In The Physiology of Reproduction 3rd edition. Edited by: Neill JD. St. Louis: Elsevier; 2006:359-403.

2. Noyes RW, Hertig AT, Rock J: Dating the endometrial biopsy. Fertil Steril 1950, I:3-I7.

3. Coutifaris C, Myers ER, Guzick DS, Diamond MP, Carson SA, Legro RS, McGovern PG, Schlaff WD, Carr BR, Steinkampf MP, Silva S, Vogel DL, Leppert PC: Histological dating of timed endometrial biopsy tissue is not related to fertility status. Fertil Steril 2004, 82:1264-1272.

4. Murray MJ, Meyer WR, Zaino RJ, Lessey BA, Novotny DB, Ireland K Zeng D, Fritz MA: A critical analysis of the accuracy, reproducibility, and clinical utility of histologic endometrial dating in fertile women. Fertil Steril 2004, 8 I: I333-1343.

5. Kao LC, Tulac S, Lobo S, Imani B, Yang JP, Germeyer A, Osteen K, Taylor RN, Lessey BA, Giudice LC: Global gene profiling in human endometrium during the window of implantation. Endocrinology 2002, 143:2119-2138.

6. Carson DD, Lagow E, Thathiah A Al-Shami R, Farach-Carson MC Vernon M, Yuan L, Fritz MA, Lessey B: Changes in gene expression during the early to mid-luteal (receptive phase) transition in human endometrium detected by high-density microarray screening. Mol Hum Reprod 2002, 8:87I-879.

7. Borthwick JM, Charnock-Jones DS, Tom BD, Hull ML, Teirney R, Phillips SC, Smith SK: Determination of the transcript profile of human endometrium. Mol Hum Reprod 2003, 9:19-33.

8. Riesewijk A, Martin J, van Os R, Horcajadas JA, Polman J, Pellicer A, Mosselman S, Simon C: Gene expression profiling of human 
endometrial receptivity on days $\mathrm{LH}+2$ versus $\mathrm{LH}+7$ by microarray technology. Mol Hum Reprod 2003, 9:253-264.

9. $\mathrm{Ace} \mathrm{Cl}$, Okulicz WC: Microarray profiling of progesterone-regulated endometrial genes during the rhesus monkey secretory phase. Reprod Biol Endocrinol 2004, 2:54.

10. Punyadeera C, Dassen H, Klomp J, Dunselman G, Kamps R, Dijcks F Ederveen A, de Goeij A, Groothuis P: Oestrogen-modulated gene expression in the human endometrium. Cell Mol Life Sci 2005, 62:239-250

II. Mirkin S, Arslan M, Churikov D, Corica A, Diaz JI, Williams S, Bocca S, Oehninger S: In search of candidate genes critically expressed in the human endometrium during the window of implantation. Hum Reprod 2005, 20:2 104-21 I7.

12. Horcajadas HA, Riesewijk A, Martin J, Cervero A, Mosselman S, Pellicer A, Simon C: Global gene expression profiling of human endometrial receptivity. J Reprod Immunol 2004, 63:4I -49.

13. Ponnampalam AP, Weston GC, Trajstman AC, Susil B, Rogers PA: Molecular classification of human endometrial cycle stages by transcriptional profiling. Mol Hum Reprod 2004, 10:879-893.

14. Talbi S, Hamilton AE, Vo KC, Tulac S, Overgaard MT, Dosiou C, Le Shay N, Nezhat CN, Kempson R, Lessey BA, Nayak NR, Giudice LC Molecular phenotyping of human endometrium distinguishes menstrual cycle phases and underlying biological processes in normo-ovulatory women. Endocrinology 2006 , 147(3): | 097-I I2I.

15. Pole JC, Gold LI, Orton T, Huby R, Carmichael PL: Gene expression changes induced by estrogen and selective estrogen receptor modulators in primary-cultured human endometrial cells: signals that distinguish the human carcinogen tamoxifen. Toxicology 2005, 206:9I-109.

16. Carroll JS, Liu XS, Brodsky AS, Li W, Meyer CA, Szary AJ, Eeckhoute J, Shao W, Hestermann EV, Geistlinger TR, Fox EA, Silver PA, Brown $\mathrm{M}$ : Chromosome-wide mapping of estrogen receptor binding reveals long-range regulation requiring the forkhead protein FoxAl. Cell 2005, I 22:33-43.

17. Tan YF, Li FX, Piao YS, Sun XY, Wang YL: Global gene profiling analysis of mouse uterus during the oestrous cycle. Reproduction 2003, I 26: 17|-182.

18. Yang S, Fang Z, Gurates B, Tamura M, Miller J, Ferrer K, Bulun SE: Stromal PRs mediate induction of I7beta-hydroxysteroid dehydrogenase type 2 expression in human endometrial epithelium: a paracrine mechanism for inactivation of E2. Mo Endocrinol 200I, 15:2093-2105.

19. Mustonen MV, Isomaa VV, Vaskivuo T, Tapanainen J, Poutanen MH, Stenback F, Vihko RK, Vihko PT: Human I 7beta-hydroxysteroid dehydrogenase type 2 messenger ribonucleic acid expression and localization in term placenta and in endometrium during the menstrual cycle. I Clin Endocrinol Metab 1998, 83:1319-1324

20. Bergqvist $A$, Ferno $M$ : Oestrogen and progesterone receptors in endometriotic tissue and endometrium: comparison of different cycle phases and ages. Hum Reprod 1993, 8:221 I-2227.

21. Lessey BA, Killam AP, Metzger DA, Haney AF, Greene GL, McCarty KS Jr: Immunohistochemical analysis of human uterine estrogen and progesterone receptors throughout the menstrual cycle. J Clin Endocrinol Metab 1988, 67:334-340.

22. Mote PA, Balleine RL, McGowan EM, Clarke CL: Heterogeneity of progesterone receptors $A$ and $B$ expression in human endometrial glands and stroma. Hum Reprod 2000, I 5(Suppl 3):48-56

23. Mylonas I, Jeschke U, Shabani N, Kuhn C, Balle A, Kriegel S, Kupka MS, Friese K: Immunohistochemical analysis of estrogen receptor alpha, estrogen receptor beta and progesterone receptor in normal human endometrium. Acta Histochem 2004 106:245-252.

24. Brayman M, Thathiah A, Carson DD: MUCI: a multifunctional cell surface component of reproductive tissue epithelia. Reprod Biol Endocrinol 2004, 2:4.

25. Tulac S, Overgaard MT, Hamilton AE, Jumbe NL, Suchanek E, Giudice LC: Dickkopf-I, an inhibitor of Wnt signaling, is regulated by progesterone in human endometrial stromal cells. J Clin Endocrinol Metab 2006, 91:|453-|46|.

26. Dunn CL, Critchley HO, Kelly RW: IL-I5 regulation in human endometrial stromal cells. J Clin Endocrinol Metab 2002, 87: $1898-190 \mid$
27. Okada H, Nakajima T, Sanezumi M, lkuta A, Yasuda K, Kanzaki H: Progesterone enhances interleukin- 15 production in human endometrial stromal cells in vitro. J Clin Endocrinol Metab 2000, 85:4765-4770.

28. Muller WA: New mechanisms and pathways for monocyte recruitment. J Exp Med 200I, 194:F47-5I.

29. Horcajadas JA, Riesewijk A, Polman J, van Os R, Pellicer A, Mosselman $S$, Simon C: Effect of controlled ovarian hyperstimulation in IVF on endometrial gene expression profiles. Mol Hum Reprod 2005, II: 195-205.

30. Bhatt $\mathrm{H}$, Brunet $\mathrm{L}$, Stewart $\mathrm{CL}$ : Uterine expression of leukemia inhibitory factor coincides with the onset of blastocyst implantation. Proc Natl Acad Sci USA I 99 I, 88: I | 408-I I 4 I2.

3I. Stewart CL, Kaspar P, Brunet LJ, Bhatt H, Gadi I, Kontgen F, Abbondanzo S): Blastocyst implantation depends on maternal expression of leukaemia inhibitory factor. Nature 1992, 359:76-79.

32. Kondera-Anasz Z, Sikora J, Mielczarek-Palacz A: Leukemia inhibitory factor: an important regulator of endometrial function. Am J Reprod Immunol 2004, 52:97-105.

33. Hambartsoumian E: Endometrial leukemia inhibitory factor (LIF) as a possible cause of unexplained infertility and multiple failures of implantation. Am J Reprod Immunol 1998, 39: $137-143$

34. Tsai HD, Chang CC, Hsieh YY, Lo HY: Leukemia inhibitory factor expression in different endometrial locations between fertile and infertile women throughout different menstrual phases. J Assist Reprod Genet 2000, 17:415-418.

35. Kitaya $\mathrm{K}$, Yamaguchi $\mathrm{T}$, Honjo $\mathrm{H}$ : Central role of interleukin- $\mathbf{5}$ in postovulatory recruitment of peripheral blood CDI6(-) natural killer cells into human endometrium. I Clin Endocrinol Metab 2005, 90:2932-2940.

36. Daly DC, Tohan N, Doney TJ, Maslar IA, Riddick DH: The significance of lymphocytic-leukocytic infiltrates in interpreting late luteal phase endometrial biopsies. Fertil Steril 1982, 37:786-79|

37. loachim EE, Kitsiou E, Carassavoglou C, Stefanaki S, Agnantis NJ Immunohistochemical localization of metallothionein in endometrial lesions. J Pathol 2000, 191:269-273.

38. Sies H: Strategies of antioxidant defense. Eur J Biochem 1993 , 215:213-219.

39. Kingsley PD, Whitin JC, Cohen HJ, Palis J: Developmental expression of extracellular glutathione peroxidase suggests antioxidant roles in deciduum, visceral yolk sac, and skin. Mol Reprod Dev 1998, 49:343-355

40. Lydon JP, DeMayo FJ, Conneely OM, O'Malley BW: Reproductive phenotpes of the progesterone receptor null mutant mouse. J Steroid Biochem Mol Biol 1996, 56:67-77.

41. Critchley HO, Jones RL, Lea RG, Drudy TA, Kelly RW, Williams AR, Baird DT: Role of inflammatory mediators in human endometrium during progesterone withdrawal and early pregnancy. J Clin Endocrinol Metab 84:240-248.

42. Critchley HO, Kelly RW, Brenner RM, Baird DT: The endocrinology of menstruation--a role for the immune system. Clin Endocrinol (Oxf) 200I, 55:70I-7I0.

43. Booker SS, Jayanetti C, Karalak S, Hsiu JG, Archer DF: The effect of progesterone on the accumulation of leukocytes in the human endometrium. Am J Obstet Gynecol 1994, I71: I39- I42.

44. Casslen B, Sandberg T, Gustavsson B, Willen R, Nilbert M: Transforming growth factor betal in the human endometrium. Cyclic variation, increased expression by estradiol and progesterone, and regulation of plasminogen activators and plasminogen activator inhibitor-I. Biol Reprod 1998, 58:1343-1350.

45. Schatz F, Krikun G, Runic R, Wang EY, Hausknecht V, Lockwood CJ: Implications of decidualization-associated protease expression in implantation and menstruation. Semin Reprod Endocrino 1999, 17:3-12.

46. Cornet PB, Picquet C, Lemoine P, Osteen KG, Bruner-Tran KL, Tabibzadeh S, Courtoy PJ, Eeckhout Y, Marbaix E, Henriet P: Regulation and function of LEFTY-A/EBAF in the human endometrium. mRNA expression during the menstrual cycle, control by progesterone, and effect on matrix metalloprotineases. J Biol Chem 2002, 277:42496-42504. 
47. Salamonsen LA: Matrix metalloproteinases and their tissue inhibitors in endocrinology. Trends Endocrinol Metab 1996, 7:28-34.

48. Salamonsen LA, Woolley DE: Menstruation: induction by matrix metalloproteinases and inflammatory cells. J Reprod Immunol 1999, 44: I-27.

49. Jones RL, Kelly RW, Critchley HO: Chemokine and cyclooxygenase-2 expression in human endometrium coincides with leukocyte accumulation. Hum Reprod 1997, I 2:1300-1306.

50. Pickles VR: Prostaglandins in the human endometrium. Int J Fertil 1967, I 2:335-338.

5I. Dosiou C, Giudice LC: Natural killer cells in pregnancy and recurrent pregnancy loss: endocrine and immunologic perspectives. Endocr Rev 2005, 26:44-62.

52. King AE, Critchley HO, Kelly RW: The NF-kappaB pathway in human endometrium and first trimester decidua. Mol Hum Reprod 2001, 7:175-183.

53. Bonhoff A, Naether O, Johannisson E, Bohnet HG: Morphometric characteristics of endometrial biopsies after different types of ovarian stimulation for infertility treatment. Fertil Steril 1993, 59:560-566.

Publish with Bio Med Central and every scientist can read your work free of charge

"BioMed Central will be the most significant development for disseminating the results of biomedical research in our lifetime. "

Sir Paul Nurse, Cancer Research UK

Your research papers will be:

- available free of charge to the entire biomedical community

- peer reviewed and published immediately upon acceptance

- cited in PubMed and archived on PubMed Central

- yours - you keep the copyright 